\title{
CHRONIC OBSTRUCTIVE PULMONARY DISEASE
}

\section{Nutritional enhancement of exercise performance in chronic obstructive pulmonary disease: a randomised controlled trial}

\author{
M C Steiner, R L Barton, S J Singh, M D L Morgan
}

Thorax 2003;58:745-75

See end of article for authors' affiliations

.....................

Correspondence to: $\operatorname{Dr} M$ C Steiner, Institute for Lung Health, Department of Respiratory Medicine, Glenfield Hospital, Leicester LE3 9QP, UK; michael.steiner@uhl-tr.nhs.uk

Revised version received 4 November 2002

Accepted for publication 12 April 2003

\begin{abstract}
Background: Pulmonary rehabilitation is effective in improving exercise performance and health status in chronic obstructive pulmonary disease (COPD). However, the role of nutritional support in the enhancement of the benefits of exercise training has not been explored. A double blind, randomised, controlled trial of carbohydrate supplementation was undertaken in patients attending outpatient pulmonary rehabilitation.

Methods: 85 patients with COPD were randomised to receive a $570 \mathrm{kcal}$ carbohydrate rich supplement or a non-nutritive placebo daily for the duration of a 7 week outpatient pulmonary rehabilitation programme. Primary outcome measures were peak and submaximal exercise performance using the shuttle walk tests. Changes in health status, body composition, muscle strength, and dietary macronutrient intake were also measured.

Results: Patients in both the supplement and placebo groups increased shuttle walking performance and health status significantly. There was no statistically significant difference between treatment groups in these outcomes. Patients receiving placebo lost weight whereas supplemented patients gained weight. In well nourished patients $\left(B M I>19 \mathrm{~kg} / \mathrm{m}^{2}\right)$ improvement in incremental shuttle performance was significantly greater in the supplemented group (mean difference between groups: $27(95 \% \mathrm{Cl} 1$ to 53) $\mathrm{m}, \mathrm{p}<0.05)$. Increases in incremental shuttle performance correlated with increases in total carbohydrate intake.

Conclusions: When universally prescribed, carbohydrate supplementation does not enhance the rehabilitation of patients with COPD. This study suggests that exercise training results in negative energy balance that can be overcome by supplementation and that, in selected patients, this may improve the outcome of training. The finding of benefit in well nourished patients may suggest a role for nutritional supplementation beyond the treatment of weight loss in COPD.
\end{abstract}

with a reduction in normal food intake. ${ }^{10}$ For appetite to be maintained, supplementation may need to be combined with an anabolic stimulus such as exercise. However, few studies have done this and none have explored the effect of carbohydrate supplementation in enhancing the benefits of training. Importantly, the benefits of carbohydrate provision for training and performance in sport are not restricted to underweight individuals. This may also be true for patients with COPD who are not overtly malnourished.

We have performed a double blind, randomised, controlled trial of nutritional supplementation in COPD patients undergoing pulmonary rehabilitation. Because our aim was to augment exercise training, patients randomised to the treatment arm were supplied with a carbohydrate rich supplement. Our hypothesis was that this intervention would enhance the physical outcome of pulmonary rehabilitation and that these benefits would not be confined to underweight patients. A secondary aim of the study was to measure the changes in health status, body weight, and composition resulting from this therapeutic combination.

\section{METHODS}

\section{Patients}

Patients referred to the pulmonary rehabilitation programme who met clinical and spirometric criteria for COPD ${ }^{11}$ were assessed consecutively for inclusion in the study. Patients were stable at recruitment and medical treatment had been optimised in the outpatient clinic before referral to rehabilitation. Patients were excluded if they were unsuitable for the addition, there are difficulties achieving adequate calorie intake in elderly subjects who may offset supplementation 
exercise component of the programme due to other conditions such as cardiac, neuropsychiatric, or musculoskeletal disorders. Additional exclusion criteria were a diagnosis of diabetes or glucose intolerance and a body mass index (BMI) of $>30 \mathrm{~kg} / \mathrm{m}^{2}$. These exclusion criteria were applied because it was felt that nutritional supplementation would be inappropriate in these situations. All patients gave written informed consent for participation in the study. Ethical approval for the study was granted by the Leicestershire research ethics committee.

\section{Study design}

All patients participated in the outpatient pulmonary rehabilitation programme at Glenfield Hospital. After baseline measurements had been taken, patients were randomised to receive a carbohydrate rich nutritional supplement three times a day for the duration of the rehabilitation programme or a non-nutritive placebo. Treatment was allocated in blocks of four from a preprepared randomisation list. Treatment was allocated and dispensed independently by a member of staff in the pharmacy department who was not involved with the conduct of the study. Both the investigators and the patients were blinded to the treatment allocation. Unblinding of the study did not occur until the last patient had completed their final assessment.

\section{Outcome measurements}

Study assessments were made before randomisation and within 1 week of completion of the rehabilitation programme.

\section{Physical performance}

Walking performance was measured using the incremental (ISWT) and endurance (ESWT) shuttle walk tests. The ISWT is a symptom limited, maximal, field exercise test. ${ }^{12}$ Performance in the ISWT has been shown to be predictive of peak oxygen consumption $\left(\mathrm{VO}_{2}\right),{ }^{13}$ and the test is reproducible after a single practice walk.

Endurance performance was measured using the ESWT. ${ }^{14}$ This is a constant work rate field exercise test. Walking speed is constant and is set at the equivalent of $85 \%$ of the predicted peak $\mathrm{VO}_{2}$ estimated during the ISWT. The total time walked (excluding the warm-up time) is recorded.

Isometric quadriceps strength (QS) was measured. Patients were seated upright with the knee flexed at $90^{\circ}$. A strap was placed around the lower shin and connected by a chain to a pressure transducer (Sprint, Loughborough, UK). The subject was asked to maximally extend the knee against the strap. Two groups of three attempts were performed with 5-10 minutes rest between them. The highest value of the six attempts was recorded.

Isometric handgrip strength (HGS) was measured using a handgrip dynamometer (Takei Instruments, Japan). After a practice attempt, strength was measured twice in each hand. The mean of the highest values in the right and left hand was recorded. Results are expressed as $\mathrm{kg}$ force.

\section{Health status}

Disease specific health status was measured using the Self Reported Chronic Respiratory Questionnaire (CRQ-SR). This has been developed from the interviewer led $\mathrm{CRQ}^{15}$ to allow patients to complete the questionnaire without the need for a time consuming interview from a member of staff. ${ }^{16}$ The questionnaire scores four domains-dyspnoea, fatigue, emotion and mastery. The results are presented as mean scores per question in each dimension. The threshold for a clinically significant change for each dimension has been previously identified as $0.5 .^{17}$

\section{Body weight and composition}

Body weight was measured in light clothing using digital scales (Seca, UK) to the nearest $100 \mathrm{~g}$. Height was measured to the nearest centimetre using a wall mounted stadiometer. Body mass index was calculated as weight $/$ height $^{2}\left(\mathrm{~kg} / \mathrm{m}^{2}\right)$.

Body composition was measured using dual energy $x$ ray absorptiometry (DEXA) (Lunar Expert-XL Bone Densitometer, Lunar Radiation Corporation, Madison, USA). This provides a three compartment model of body composition giving values for bone mass, lean mass, and fat mass. These are derived using software provided by the manufacturer (Software Version 1.91). We have recently established the reproducibility of body composition measurements by DEXA over 7 weeks in stable COPD patients. ${ }^{18}$

\section{Pulmonary rehabilitation programme}

Patients attended the outpatient rehabilitation programme at Glenfield Hospital. They attended twice weekly for a total of 14 sessions, lasting at least 7 weeks. Missed sessions were added to the end of the programme.

The endurance training component of the programme comprised weekly sessions of endurance walking exercises together with a home walking programme. Patients were asked to walk at a speed equivalent to $85 \%$ of the predicted peak $\mathrm{VO}_{2}$ achieved during the ISWT at their initial assessment. Walking times were increased progressively during the course of the programme. At each training session adherence to the training programme was monitored, walking speeds checked, and new targets set for walking times.

Patients also performed a weekly circuit of low impact conditioning exercises designed to increase suppleness and flexibility. The duration of these exercises was increased during the programme but there was no specific progressive weight training.

Each rehabilitation session included education sessions covering a range of topics including disease pathology, treatment, diet, and relaxation.

\section{Nutritional supplementation}

Patients allocated to the supplement arm of the study were asked to drink a $125 \mathrm{ml}$ supplement (Respifor, Nutricia, Netherlands) three times per day for the duration of their attendance at rehabilitation. The supplement provided $570 \mathrm{kcal}$ daily in the following macronutrient composition: carbohydrate $60 \%$, fat $20 \%$, protein $20 \%$. This supplement was chosen because its macronutrient profile and low volume was thought particularly suitable for the needs of exercising patients. Patients in the placebo group received an identically packaged and flavoured non-nutritive placebo.

Patients were supplied with cartons each week when attending the rehabilitation sessions. At each visit patients were interviewed by a qualified dietician (RLB). During these interviews self-reported compliance, adverse events, and changes to concomitant therapy were recorded.

\section{Dietary intake}

The effect of the intervention on normal dietary intake was assessed using a three-day food diary. ${ }^{19}$ This was performed before randomisation and again during the second half of the rehabilitation programme (weeks 4-7). Standard food portion sizes $^{20}$ were used to estimate food weights. Mean daily calorie and macronutrient intake was calculated by entering food records into a computerised version of food composition tables (Microdiet version 9.1, University of Salford, UK). ${ }^{21}$

\section{Data analysis}

Mean increases in ISWT performance from our rehabilitation programme are around $50 \mathrm{~m}$. The clinical significance of further increases in performance resulting from treatment adjunctive to rehabilitation is unknown but we judged that an additional increase of $35 \mathrm{~m}$ would be of functional benefit to patients. The sample size was calculated (with $80 \%$ power) to ensure we would detect this additional increase in ISWT performance in the supplement group, assuming a $25 \%$ dropout 
Table 1 Mean (SD) baseline characteristics of patients entering the study.

\begin{tabular}{|c|c|c|}
\hline & $\begin{array}{l}\text { Supplement } \\
(\mathrm{n}=42)\end{array}$ & $\begin{array}{l}\text { Placebo } \\
(n=43)\end{array}$ \\
\hline$F: M$ & $16: 26$ & $16: 27$ \\
\hline Age & $66(9.0)$ & $68(8.0)$ \\
\hline $\mathrm{FEV}_{1}$ (I) & $0.91(0.42)$ & $0.84(0.31)$ \\
\hline $\mathrm{FEV}_{1}(\%$ predicted) & $34.7(13.6)$ & 34.4 (14.3) \\
\hline Weight $(\mathrm{kg})$ & $67.4(14.2)$ & $65.4(11.9)$ \\
\hline BMI $\left(\mathrm{kg} / \mathrm{m}^{2}\right)$ & $23.9(3.5)$ & $23.5(3.8)$ \\
\hline Lean mass $(\mathrm{kg})$ & $43.3(9.4)$ & $42.4(9.0)$ \\
\hline Fat mass $(\mathrm{kg})$ & $20.8(8.4)$ & $19.4(8.9)$ \\
\hline ISWT (m) & $210(113)$ & 220 (123) \\
\hline $\operatorname{ESWT}(s)^{*}$ & 163 (132) & $219(159)$ \\
\hline HGS (kg force) & $27.6(7.2)$ & $27.1(8.6)$ \\
\hline$Q S(N)$ & 305 (105) & $305(113)$ \\
\hline Total calorie intake (kcal) & $1832(536)$ & 1719 (494) \\
\hline Carbohydrate intake $(\mathrm{g})$ & $210(60)$ & 208 (71) \\
\hline Protein intake (g) & $73(20)$ & $68(21)$ \\
\hline Fat intake (g) & $75(30)$ & $70(23)$ \\
\hline
\end{tabular}

$\mathrm{FEV}_{1}=$ forced expiratory volume in 1 second; $\mathrm{BMI}=$ body mass index; ISWT, ESWT=incremental and endurance shuttle walk tests; $\mathrm{HGS}=$ hand grip strength; $\mathrm{QS}=$ quadriceps strength. Dietary macronutrient values are mean daily intakes. There was no statistically significant difference between treatment groups at baseline.

*Median (IQR) values.

rate from rehabilitation. To achieve this we needed to recruit 85 patients, with 56 completing the study.

We hypothesised that undernourished patients might respond differently to our intervention. A subgroup analysis of the main study outcomes was therefore made in patients with a BMI above and below $19 \mathrm{~kg} / \mathrm{m}^{2}$. This is an accepted lower limit of normal for BMI. ${ }^{22}$
Because patients who dropped out were unable to attend for repeat assessments, the analysis was based on treatment received. Between group changes for normally distributed variables were compared with analysis of covariance (ANCOVA) using the corresponding baseline value as a covariate (Mann-Whitney $U$ test for non-parametric or ordinal data). Statistical tests were performed using SPSS Version 10 (Chicago, IL, USA).

\section{RESULTS}

Eighty five patients were recruited to the study. The treatment groups were well matched at baseline (table 1). The condition and medication of all patients was stable at the time of recruitment. Six patients were taking long term oral corticosteroids (maximum dose $7.5 \mathrm{mg}$ prednisolone daily).

The trial outline is shown in fig 1 . Sixty patients completed the trial. More patients dropped out from the supplement group $(n=17)$ than from the placebo group $\left(n=8 ; p=0.027, \chi^{2}\right.$ test). Dropouts were due to inability or reluctance to complete rehabilitation rather than refusal to consume supplement or placebo. Reasons for withdrawal are detailed in the trial outline. There was a trend to a greater dropout rate due to exacerbations of COPD in the supplement group $(n=8)$ than in the placebo group $(n=3)$, but this was not statistically significant $\left(\mathrm{p}=0.058, \chi^{2}\right.$ test $)$. One patient withdrew because he was unable to tolerate the cartons of drink but he subsequently also withdrew from rehabilitation. For those completing the trial the median number of rehabilitation sessions missed was one in both groups (supplement group: range $0-5$, placebo group: range $0-8$ ). One patient in the supplement group completed the final performance and health status assessments but suffered a ruptured abdominal aortic aneurysm and died before his final DEXA scan.

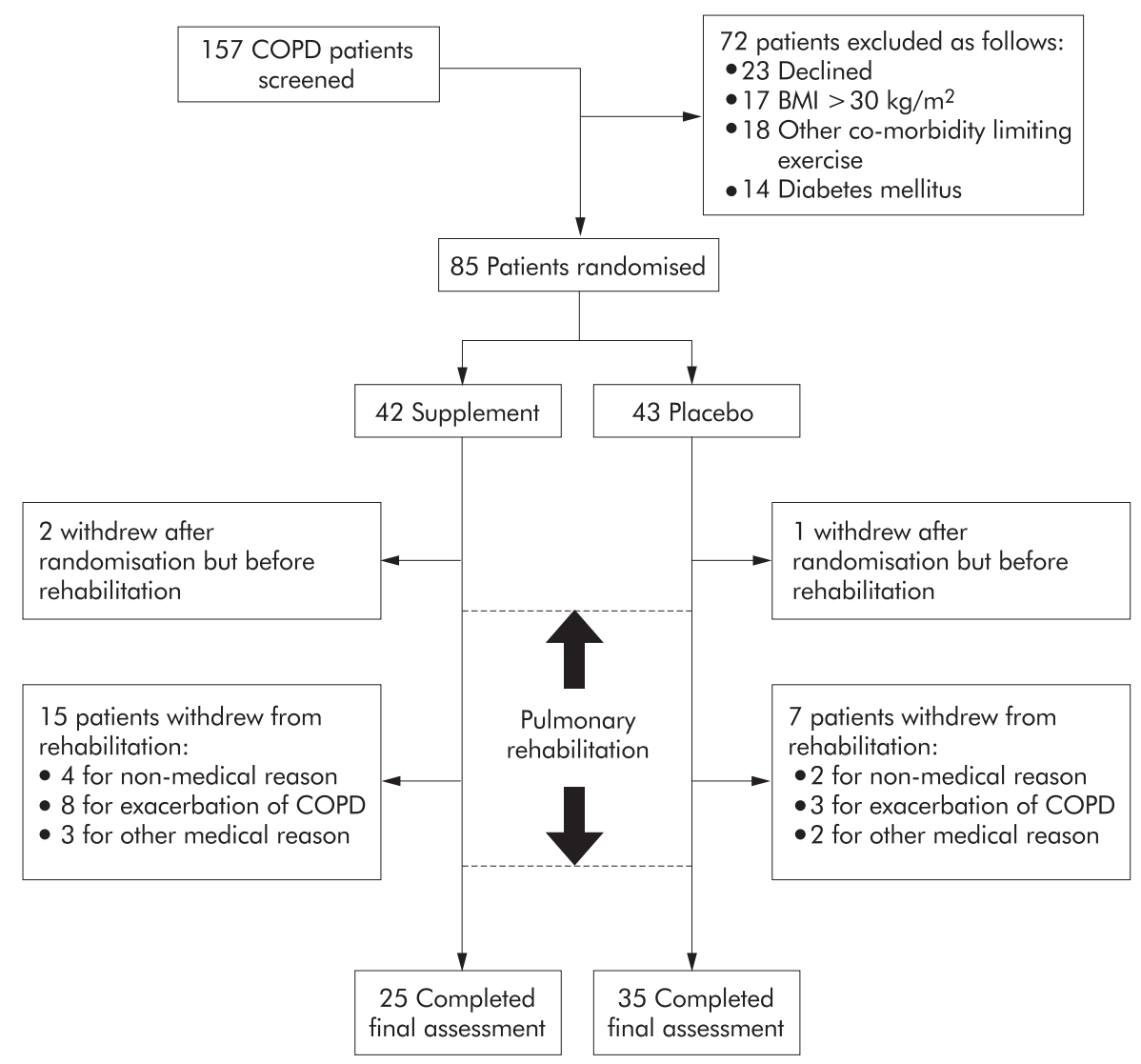

Figure 1 Trial outline based on completion of shuttle walk tests. 
Table 2 Within group changes in daily macronutrient intake during study period

\begin{tabular}{|c|c|c|c|c|}
\hline & \multicolumn{2}{|l|}{ Supplement } & \multicolumn{2}{|l|}{ Placebo } \\
\hline & Mean change & $95 \% \mathrm{Cl}$ & Mean change & $95 \% \mathrm{Cl}$ \\
\hline Total calories (kcal) & $394 \dagger$ & 248 to 541 & 100 & -37 to 238 \\
\hline Carbohydrate (g) & $63.7 \dagger$ & 41.7 to 85.7 & 4.5 & -11.3 to 20.3 \\
\hline Fat (g) & 6.3 & -3.4 to 15.9 & 6.1 & -2.3 to 14.5 \\
\hline Protein $(\mathrm{g})$ & $25.2 \dagger$ & 19.3 to 31.1 & $6.1^{*}$ & 0.3 to 11.8 \\
\hline
\end{tabular}

Mean changes are calculated by subtracting baseline values from those obtained during the study period. Within group comparisons made using the paired Student's $t$ test. Figures include contribution from supplement cartons (additional daily intake: total energy: $570 \mathrm{kcal}$, carbohydrate: $84 \mathrm{~g}$, fat: $12.5 \mathrm{~g}$, protein: 28 g). ${ }^{*} p<0.05 ; \dagger p<0.01$.

Self-reported compliance with the supplement (\% cartons taken/cartons prescribed) was excellent in both groups (supplement group $97.6 \%$, placebo group 98.8\%). Overall macronutrient intake increased significantly in the supplement group (table 2), but the effect of supplementation was attenuated by a reduction in food intake. As a result, the mean increase in calorie and macronutrient intake in the supplemented group was equivalent to about $70 \%$ of the prescribed supplement.

Changes after rehabilitation within each treatment group are shown in table 3 . There were significant increases in shuttle walking performance in both groups. Although there was a statistically significant increase in quadriceps strength in the supplement group, this was probably too small to be of clinical relevance. Patients in the supplement group gained weight while those in the placebo group lost weight. This was principally due to changes in fat mass. Health status measured by the CRQ-SR increased significantly in all domains in both the supplement group (mean (95\% CI) changes; Dyspnoea: 0.7 (0.2 to 1.1), $\mathrm{p}<0.01$; Fatigue: 0.6 (0.3 to 1.0$), \mathrm{p}<0.05$; Emotion: 0.6 (0.3 to 1.0), p<0.01; Mastery: 0.4 (0.01 to 0.8 ), $\mathrm{p}<0.05$ ) and the placebo group (Dyspnoea: 1.0 (00.6 to 1.4), $\mathrm{p}<0.01$; Fatigue: 0.7 (0.4 to 1.1), $\mathrm{p}<0.01$; Emotion: 0.5 (0.2 to $0.8), \mathrm{p}<0.01$; Mastery: 0.9 (0.5 to 1.3$), \mathrm{p}<0.01$ ).

Table 3 also shows the between group differences in changes in outcome variables after rehabilitation. Because there was an uneven dropout rate between the groups, a further analysis of covariance was performed to determine if this explained any differences between treatment groups. When patients who dropped out were compared with those who completed the study, they were found to have generally lower baseline values for age, BMI, $\mathrm{FEV}_{1}$ (\% predicted), and quadriceps strength. These variables were therefore used as covariates in this analysis. This did not substantially affect the between group differences or levels of significance in the study as a whole or the subgroup analysis.

Both incremental and endurance shuttle walking performance increased more in the supplement group but these differences were not statistically significant. There were no significant differences in the change in health status between the groups. Weight changes between the supplement and placebo groups were significantly different (table 3 ). These changes were predominantly in the fat compartment. Changes in ISWT and fat mass correlated with increases in carbohydrate intake (ISWT: $r=0.336, p=0.011$; fat mass: $r=0.337, \mathrm{p}=0.010$; fig 2).

\section{Subgroup analysis}

The results of a subgroup analysis of patients with BMI $>19 \mathrm{~kg} / \mathrm{m}^{2}$ are shown in table 4 . Fifty two patients fell into this group (22 supplement, 30 placebo). Data on patients with BMI $<19 \mathrm{~kg} / \mathrm{m}^{2}$ are also presented although the numbers in this group were small ( 3 supplement, 5 placebo). Baseline characteristics in the well nourished subgroup did not differ between treatment groups. In this subgroup there was a significantly greater increase in ISWT in supplemented patients than in those receiving placebo. The differences in change in ESWT, weight, and fat mass were also of greater magnitude. In addition, the relationship between changes in carbohydrate intake and changes in fat mass $(r=0.42, \mathrm{p}=0.003)$ and ISWT $(r=0.46, \mathrm{p}=0.001)$ were stronger. Normal food intake was better maintained in the well nourished subgroup resulting in greater increases in carbohydrate intake in the supplemented group than in the placebo group (mean (95\% CI) change in carbohydrate: 73 (52 to 93 ) g $v-5$ (-21 to 10) g).

Table 3 Within group changes and between group differences in outcome variables after pulmonary rehabilitation

\begin{tabular}{|c|c|c|c|c|}
\hline & \multicolumn{2}{|l|}{ Within group changes } & \multicolumn{2}{|c|}{ Between group differences } \\
\hline & Supplement & Placebo & Mean difference & $p$ value \\
\hline \multicolumn{5}{|l|}{ Physical performance } \\
\hline ISWT (m) & 60.0 (39.1 to 80.9$) \ddagger$ & $42.6(25.0$ to 60.1$) \ddagger$ & 18 (-8 to 45$)$ & 0.174 \\
\hline ESWT $(s)^{*}$ & $328(223$ to 554$) \ddagger$ & 191 (131 to 304)‡ & $103(-55$ to 255$)$ & 0.182 \\
\hline HGS (kg force) & $0.64(-0.03$ to 1.31$)$ & $-0.05(-0.78$ to 0.68$)$ & $0.93(-0.04$ to 1.89$)$ & 0.060 \\
\hline QS (N) & $17.4(3.3$ to 31.6$) \dagger$ & $3.6(-8.1$ to 15.3$)$ & $16.5(-1.2$ to 34.2$)$ & 0.068 \\
\hline \multicolumn{5}{|l|}{ Body composition } \\
\hline Weight (kg) & $0.63(0.03$ to 1.23$) \dagger$ & $-0.58(-1.11$ to -0.05$) \dagger$ & 1.23 (0.42 to 2.05$)$ & 0.004 \\
\hline BMI $\left(\mathrm{kg} / \mathrm{m}^{2}\right)$ & $0.24(0.03$ to 0.44$) \dagger$ & $-0.22(-0.42$ to -0.02$) \dagger$ & $0.46(0.17$ to 0.75$)$ & 0.002 \\
\hline Lean mass $(\mathrm{kg})$ & $0.13(-0.43$ to 0.70$)$ & $0.63(0.18$ to 1.08$) \ddagger$ & $-0.51 \quad(-1.23$ to 0.20$)$ & 0.156 \\
\hline Fat mass $(\mathrm{kg})$ & $0.67(0.03$ to 1.30$) \dagger$ & $-0.76(-1.27$ to -0.25$) \ddagger$ & $1.46(0.65$ to 2.27$)$ & 0.001 \\
\hline
\end{tabular}

$\mathrm{BMI}=$ body mass index; ISWT, ESWT=incremental and endurance shuttle walk tests; HGS=hand grip strength; QS=quadriceps strength Within group changes: Mean $(95 \% \mathrm{Cl})$ changes are given. Unless specified, comparisons are made using the paired student's $t$ test. Changes were calculated by subtracting baseline from post rehabilitation measurements. Negative values denote a decrease over the study period. Between group differences: Mean $(95 \% \mathrm{CI})$ differences are adjusted for baseline using ANCOVA. Negative values indicate higher values in the placebo group. *Median values are given. Within group changes compared using Wilcoxon signed ranks test. Between group comparisons made using Mann-Whitney $U$ test. test. $<0.05 ; \ddagger p<0.01$ 

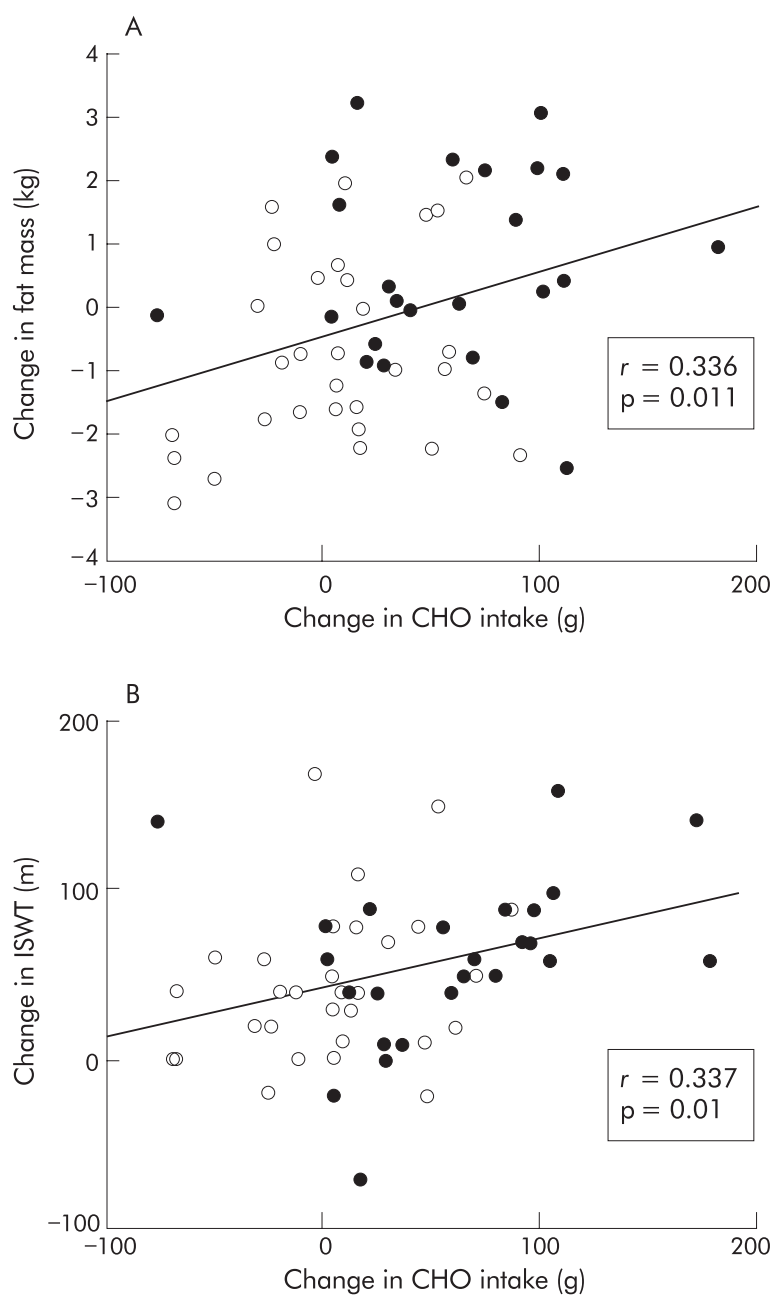

Figure 2 Relationship between changes in carbohydrate intake and changes in (A) fat mass and (B) ISWT performance in placebo group (open circles) and supplement group (closed circles).

$\mathrm{CHO}=$ carbohydrate. Pearson correlation used to calculate $r$ values.

\section{DISCUSSION}

We report the results of a randomised controlled trial of nutritional support in patients with COPD undergoing pulmonary rehabilitation. This trial differs from previous investigations because improving physical performance rather than nutritional status was the principal aim of the study. The combina- tion of nutritional supplementation and exercise training was successful in increasing weight and energy intake in our patients. In unselected patients nutritional supplementation did not significantly enhance the benefits of pulmonary rehabilitation. However, in well nourished patients (BMI >19 kg/ $\mathrm{m}^{2}$ ) the increase in ISWT after training was significantly greater in the supplemented group. Moreover, the magnitude of changes in ESWT and weight were also greater in well nourished patients. This suggests a potential role for nutritional support in enhancing physical performance in this group of patients.

Our results demonstrate marked differences in the pattern of weight change in the supplement and placebo groups. Rehabilitation resulted in weight loss in the placebo group, whereas those in the supplement group gained weight. Notably, these changes in weight were due to alterations in fat rather than lean mass. Lean mass appeared to increase significantly in the placebo group while in the supplement group it was unchanged. The explanation for this is unclear, but the finding of an isolated within group change needs to be interpreted with caution. Importantly, in contrast to the changes in weight and fat mass, there were no significant between group changes in lean mass.

While loss of lean or fat free mass may be considered to be more relevant to function in COPD, lean mass depletion may not simply be the result of energy imbalance but reflects disordered protein metabolism due to other factors such as muscle disuse, hypoxia, or drug treatment. Many of these factors will not have been addressed by rehabilitation and supplementation. While muscle mass can be readily increased by progressive strength training, this would not be expected from an endurance training programme such as ours.

Although normal dietary intake fell in the supplement group, supplementation successfully increased calorie and macronutrient intake by around $70 \%$ of the prescribed supplement. This is in line with previous outpatient supplementation programmes in COPD. ${ }^{23}$ Changes in fat mass were related to changes in carbohydrate intake across both groups, suggesting that maintenance of normal dietary intake during supplementation was an important factor in its efficacy.

These findings suggest that exercise training results in negative energy balance in many patients, which was overcome by supplementation. Physical activity imposes a high energy cost for patients with COPD. ${ }^{24}$ The increase in physical activity for many patients who attend rehabilitation is substantial, and dietary calorie intake may be insufficient to meet this new metabolic demand. We speculate that this might also impose a limit on the amount of exercise patients can do. Nutritional supplementation might therefore confer a performance advantage by allowing greater adherence to an

\begin{tabular}{|c|c|c|c|c|c|c|}
\hline & \multicolumn{3}{|c|}{$\mathrm{BMI}<19 \mathrm{~kg} / \mathrm{m}^{2}(\mathrm{n}=8)$} & \multicolumn{3}{|c|}{$\mathrm{BMI}>19 \mathrm{~kg} / \mathrm{m}^{2}(\mathrm{n}=52)$} \\
\hline & $\begin{array}{l}\text { Mean } \\
\text { difference }\end{array}$ & $95 \% \mathrm{Cl}$ & $p$ value & $\begin{array}{l}\text { Mean } \\
\text { difference }\end{array}$ & $95 \% \mathrm{Cl}$ & $\mathrm{p}$ value \\
\hline \multicolumn{7}{|c|}{ Physical performance } \\
\hline ISWT (m) & -47 & -180 to 87 & 0.425 & 27 & 1 to 53 & 0.041 \\
\hline ESWT $(s)^{*}$ & -6 & -915 to 951 & 0.881 & 121 & -44 to 286 & 0.129 \\
\hline HGS (kg force) & -0.32 & -3.4 to 2.8 & 0.809 & 0.85 & -0.26 to 1.97 & 0.129 \\
\hline QS (N) & -2.7 & -60 to 54 & 0.910 & 16.5 & -3.1 to 36.1 & 0.097 \\
\hline \multicolumn{7}{|l|}{ Body composition } \\
\hline Weight $(\mathrm{kg})$ & -0.13 & -4.1 to 3.8 & 0.940 & 1.50 & 0.68 to 2.33 & 0.001 \\
\hline BMI $\left(\mathrm{kg} / \mathrm{m}^{2}\right)$ & -0.02 & -1.4 to 1.3 & 0.975 & 0.55 & 0.26 to 0.84 & 0.000 \\
\hline Lean mass (kg) & -0.95 & -2.3 to 0.42 & 0.140 & -0.42 & -1.23 to 0.39 & 0.299 \\
\hline Fat mass $(\mathrm{kg})$ & -0.19 & -3.2 to 2.8 & 0.879 & 1.74 & 0.88 to 2.60 & 0.000 \\
\hline $\begin{array}{l}\text { Mean differenc } \\
\text { using ANCOV } \\
\text { for the group w } \\
{ }^{*} \text { Median value }\end{array}$ & $175 \% \mathrm{c}$ & $\begin{array}{l}\text { ence interv } \\
\text { nall numbe }\end{array}$ & the $g$ & $B M I>19$ & $\begin{array}{l}\mathrm{m}^{2} \text { are adjusted } \\
\text { ed mean differe } \\
\text { e placebo grou }\end{array}$ & $\begin{array}{l}r \text { baseline } \\
\text { as are give }\end{array}$ \\
\hline
\end{tabular}


exercise training programme. This is supported by our finding that increases in walking performance were related to increases in carbohydrate ingestion.

We believe the improvements in performance in the supplemented group could be meaningful for many patients. The increase in ISWT in well nourished patients was $70 \%$ greater in the supplemented group than in those receiving rehabilitation alone. Furthermore, in this subgroup the increase in ESWT was 2 minutes greater in the supplement group, although this difference was not statistically significant. The ESWT is considerably more responsive to endurance training but shows greater biological variability than ISWT performance. Our study was powered to detect changes in ISWT and may therefore have been too small to detect clinically important changes in ESWT.

An improvement in performance from carbohydrate supplementation is biologically plausible. Carbohydrate is an important source of energy for endurance exercise but intramuscular stores are limited. Carbohydrate feeding can prolong endurance in healthy subjects ${ }^{25}$ and there is evidence that a high carbohydrate diet can enhance the effects of endurance training. ${ }^{26}$ Muscle glycogen stores may be lower in COPD patients ${ }^{27}$ and, like other deconditioned individuals, they are likely to be highly reliant on carbohydrate as a source of fuel for muscular contraction. ${ }^{6}$ If physical activity increases, carbohydrate availability may become an important factor in sustaining exercise.

To our knowledge this is the first study to investigate the performance benefits of carbohydrate supplementation when combined with exercise training in COPD. A recent metaanalysis of clinical trials of nutritional supplementation failed to identify significant improvements in weight or exercise capacity. ${ }^{8}$ To date, only one trial combining nutritional support and rehabilitation has been reported.$^{28}$ In this study similar changes in weight and fat mass were seen but there was no performance advantage above that of rehabilitation alone in either depleted or non-depleted patients. One major difference between this study and ours was the composition of the supplement, which was fat rather than carbohydrate rich. It is possible that fat supplementation provides sufficient energy to allow weight gain but does not meet the metabolic demands of exercising muscles.

Our finding of greater benefits from supplementation in well nourished patients contrasts with the traditional aims of nutritional support in COPD. Well nourished patients also showed larger increases in weight and fat mass and better maintenance of dietary calorie intake, suggesting that in these patients the suppression of appetite by supplementation was not as great. Some underweight COPD patients show signs of an exaggerated systemic inflammatory response leading to an increase in resting energy expenditure, appetite suppression, and progressive cachexia. ${ }^{29}$ These patients appear to respond poorly to nutritional support ${ }^{9}$ and show appetite suppression in the face of increased energy requirements. ${ }^{30}$ We conducted a subgroup analysis in patients with a BMI of $>19 \mathrm{~kg} / \mathrm{m}^{2}$ in an effort to identify and exclude patients that might fall into this "non-responder" category. We hypothesised that these patients might attenuate the effect of the supplementation in the study population as a whole. While the outcome of a subgroup analysis needs to be interpreted with caution, the results do suggest that nutritional support combined with exercise may be beneficial for patients of normal nutritional status. Prospective studies in this group of patients are needed before such treatment can be recommended in routine clinical practice. Conclusions about the effectiveness of supplementation during rehabilitation in underweight patients cannot be drawn from this study because of the small numbers of patients in this subgroup.

The dropout rate for the study is in line with our experience of pulmonary rehabilitation but the rate was greater in the supplemented group. There was also a higher dropout rate due to disease exacerbations, although this difference was just outside statistical significance. This may have occurred by chance, but we cannot rule out the possibility that carbohydrate had an adverse effect on patients suffering an exacerbation because of the increase in carbon dioxide production that results from its oxidation. This effect has been demonstrated experimentally but its clinical relevance is unclear. ${ }^{31}$ The small volume supplement we used was designed to reduce any impact this might have and be easy for patients to tolerate. Studies using this supplement have indicated there are no short term adverse effects on ventilation or respiratory quotient in COPD patients. ${ }^{32}$

Pulmonary rehabilitation is established as effective treatment for enhancing performance in COPD. The long term aim of rehabilitation is the maintenance of physical fitness through a more active lifestyle. The implication of our study is that, for some patients, this lifestyle change could also result in negative energy balance and progressive weight loss. Further studies are warranted to examine the long term effects of physical activity on nutritional status and the role of more prolonged nutritional support in this context.

In conclusion, this trial indicates that, when universally prescribed, carbohydrate rich nutritional support does not enhance the rehabilitation of patients with COPD. Our data suggest that exercise training results in negative energy balance that can be overcome by supplementation and that, in selected patients, this may improve the outcome of training. The finding of benefit in well nourished patients may suggest a role for nutritional supplementation beyond the treatment of weight loss in COPD.

\section{ACKNOWLEDGEMENTS}

This study was planned, conducted and analysed independently by the authors. Partial financial support, covering consumable costs and dietetic support, was provided by Nutricia, Zoetermeer, The Netherlands. All authors were independently employed by University Hospitals of Leicester NHS Trust. We are grateful to Dr N Taub at the Trent Institute for Health Services Research for statistical advice.

\section{Authors' affiliations}

M C Steiner, R L Barton, S J Singh, M D L Morgan , Institute for Lung Health, Department of Respiratory Medicine, Glenfield Hospital, Leicester LE3 9QP, UK

$M$ Steiner recruited patients to the study, carried out outcome measurements, analysed the data, and wrote the manuscript with the help of the other authors. S Singh was responsible for the running of the pulmonary rehabilitation programme. $\mathrm{R}$ Barton provided dietetic support and monitoring for patients who were participating in the study and helped to analyse the data. M Morgan was involved in planning the study and provided overall supervision of the project.

\section{REFERENCES}

1 Murray CJ, Lopez AD. Alternative projections of mortality and disability by cause 1990-2020: Global Burden of Disease Study. Lancet 1997:349: 1498-504.

2 Lacasse Y, Brosseau L, Milne S, et al. Pulmonary rehabilitation for chronic obstructive pulmonary disease. Cochrane Database Syst Rev 2002;(3):CD003793.

3 Griffiths TL, Burr ML, Campbell IA, et al. Results at 1 year of outpatient multidisciplinary pulmonary rehabilitation: a randomised controlled trial. Lancet 2000;355:362-8.

4 British Thoracic Society Standards of Care Subcommittee on Pulmonary Rehabilitation. BTS statement. Pulmonary rehabilitation. Thorax 2001;56:827-34.

5 Devlin JT, Williams C. Foods, nutrition and sports performance. A final consensus statement. J Sports Sci 1991;89(Suppl iii).

6 Hurley BF, Nemeth PM, Martin WH III, et al. Muscle triglyceride utilization during exercise: effect of training. J Appl Physiol 1986:60:562-7.

7 Palange $\mathbf{P}$, Forte $S$, Felli $A$, et al. Nutritional state and exercise tolerance in patients with COPD. Chest 1995;107:1206-12.

8 Ferreira IM, Brooks D, Lacasse $Y$, et al. Nutritional support for individuals with COPD: a meta-analysis. Chest 2000;117:672-8.

9 Creutzberg EC, Schols AM, Weling-Scheepers CA, et al.

Characterization of nonresponse to high caloric oral nutritional therapy 
in depleted patients with chronic obstructive pulmonary disease. Am J Respir Crit Care Med 2000;161:745-52.

10 Lewis MI, Belman M, Dorr-Uyemura L. Nutritional supplementation in ambulatory patients with chronic obstructive pulmonary disease. Am Rev Respir Dis 1987:135:1062-8.

11 British Thoracic Society. BTS guidelines for the management of chronic obstructive pulmonary disease. Thorax 1997;52(Suppl 5):S1-28.

12 Singh SJ, Morgan MD, Scott S, et al. Development of a shuttle walking test of disability in patients with chronic airways obstruction. Thorax 1992:47:1019-24

13 Singh SJ, Morgan MD, Hardman AE, et al. Comparison of oxygen uptake during a conventional treadmill test and the shuttle walking test in chronic airflow limitation. Eur Respir J 1994;7:2016-20.

14 Revill SM, Morgan MDL, Singh SJ, et al. The endurance shuttle walk: a new field test for the assessment of endurance capacity in chronic obstructive pulmonary disease. Thorax 1999;54:213-22.

15 Guyatt GH, Berman LB, Townsend $M$, et al. A measure of quality of life for clinical trials in chronic lung disease. Thorax 1987;42:773-8.

16 Williams JE, Singh SJ, Sewell L, et al. Development of a self-reported Chronic Respiratory Questionnaire (CRQ- SR). Thorax 2001:56:954-9.

17 Juniper EF, Guyatt GH, Willan A, et al. Determining a minimal important change in a disease-specific quality of life questionnaire. J Clin Epidemiol 1994;47:81-7.

18 Steiner MC, Barton RL, Singh SJ, et al. Bedside methods versus dual energy $\mathrm{X}$-ray absorptiometry for body composition measurement in COPD. Eur Respir J 2002;19:626-31.

19 Bingham S. The dietary assessment of individuals: methods, accuracy, new techniques and recommendations. Nutr Abstr Rev 1987; 57:705-42.

20 Ministry of Agriculture Fisheries and Food. Food portion sizes. 2nd ed. London: HMSO, 1993.

21 Holland B, Welch AA, Unwin ID, et al. McCance and Widdowson's the composition of foods. 5th ed. London: The Royal Society of Chemistry and The Ministry of Agriculture, Fisheries and Food, 1991

22 Willett WC, Dietz WH, Colditz GA. Guidelines for healthy weight. N Engl J Med 1999;341:427-34.
23 Stratton RJ, Elia M. A critical, systematic analysis of the use of oral nutritional supplements in the community. Clin Nutr 1999;18(Suppl 2):29-84.

24 Baarends EM, Schols AM, Pannemans DL, et al. Total free living energy expenditure in patients with severe chronic obstructive pulmonary disease. Am J Respir Crit Care Med 1997;155:549-54.

25 Coyle EF, Coggan AR, Hemmert MK, et al. Muscle glycogen utilization during prolonged strenuous exercise when fed carbohydrate. J Appl Physiol 1986;61:165-72.

26 Helge JW, Richter EA, Kiens B. Interaction of training and diet on metabolism and endurance during exercise in man. J Physiol 1996;492 Pt 1):293-306

27 Jakobsson $\mathbf{P}$, Jorfeldt L. Long-term oxygen therapy may improve skeletal muscle metabolism in advanced chronic obstructive pulmonary disease patients with chronic hypoxaemia. Respir Med 1995:89:471-6.

28 Schols AM, Soeters PB, Mostert R, et al. Physiologic effects of nutritional support and anabolic steroids in patients with chronic obstructive pulmonary disease. A placebo-controlled randomized trial. Am J Respir Crit Care Med 1995;152:1268-74.

29 Schols AM, Buurman WA, Staal van den Brekel AJ, et al. Evidence for a relation between metabolic derangements and increased levels of inflammatory mediators in a subgroup of patients with chronic obstructive pulmonary disease. Thorax 1996;51:819-24.

30 Schols AM, Creutzberg EC, Buurman WA, et al. Plasma leptin is related to proinflammatory status and dietary intake in patients with chronic obstructive pulmonary disease. Am J Respir Crit Care Med 1999; 160:1220-6.

31 Efthimiou J, Mounsey PJ, Benson DN, et al. Effect of carbohydrate rich versus fat rich loads on gas exchange and walking performance in patients with chronic obstructive lung disease. Thorax 1992;47:451-6.

32 Vermeeren MA, Wouters EF, Nelissen LH, et al. Acute effects of different nutritional supplements on symptoms and functional capacity in patients with chronic obstructive pulmonary disease. Am J Clin Nutr $2001 ; 73: 295-301$.

\section{LUNG ALERT}

\section{Can limited pulmonary resection replace lobectomy for small sized lung cancer?}

$\Delta$ Koike T, Yamato Y, Yoshiya K, et al. Intentional limited pulmonary resection for peripheral T1NOMO small-sized lung cancer. J Thorac Cardiovasc Surg 2003;125:924-8

In this study, patients with stage la peripheral non-small cell lung cancer ( $\leqslant 2 \mathrm{~cm}$ maximum diameter) underwent either standard lobectomy $(n=159)$ or limited resection (segmentectomy or wedge resection, $\mathrm{n}=74$ ). All patients were considered fit for lobectomy and limited resection was performed if the patient consented. There were no significant differences in the 3 or 5 year survival rates between the limited resection group ( 3 year $94 \% ; 5$ year $89 \%$ ) and the lobectomy group ( 3 year 97\%; 5 year 90\%), and there was no significant difference in the incidence of disease recurrence between the two groups (limited resection $(n=5)$, lobectomy $(\mathrm{n}=9))$.

This was not a randomised study and the maximum tumour diameter was significantly smaller in the limited resection group. These results are in agreement with those of a number of similar non-randomised trials, but conflict with the findings of the Lung Cancer Study Group (Ginsberg R et al, Ann Thorac Surg 1995;60:615-23). In the latter study, 247 patients were randomised to either limited resection or lobectomy and postoperative mortality and disease recurrence rates were higher in the limited resection group. Lobectomy remains the surgical procedure of choice for patients with peripheral TINO non-small cell lung cancer.

T J Warke

Specialist Registrar, Regional Respiratory Centre, Belfast City Hospital, Belfast, UK tim@dsl.pipex.com 